\title{
Polar mesosphere summer echoes during the July 2000 solar proton event
}

\author{
V. Barabash ${ }^{1}$, S. Kirkwood ${ }^{1}$, A. Feofilov ${ }^{2}$, and A. Kutepov ${ }^{2}$ \\ ${ }^{1}$ Swedish Institute of Space Physics, Box 812, S-981 28 Kiruna, Sweden \\ ${ }^{2}$ Institute for Astronomy and Astrophysics, University of Munich, D-81679 Munich, Germany \\ Received: 30 January 2003 - Revised: 30 June 2003 - Accepted: 13 August 2003 - Published: 19 March 2004
}

\begin{abstract}
The influence of the solar proton event (SPE) 1416 July 2000 on Polar Mesosphere Summer Echoes (PMSE) is examined. PMSE were observed by the Esrange VHF MST Radar (ESRAD) at $67^{\circ} 53^{\prime} \mathrm{N}, 21^{\circ} 06^{\prime} \mathrm{E}$. The $30 \mathrm{MHz}$ Imaging Riometer for Ionospheric Studies IRIS in Kilpisjärvi $\left(69^{\circ} 30^{\prime} \mathrm{N}, 20^{\circ} 47^{\prime} \mathrm{E}\right)$ registered cosmic radio noise absorption caused by ionisation changes in response to the energetic particle precipitation. An energy deposition/ion-chemical model was used to estimate the density of free electrons and ions in the upper atmosphere. Particle collision frequencies were calculated from the MSISE-90 model. Electric fields were calculated using conductivities from the model and measured magnetic disturbances. The electric field reached a maximum of $91 \mathrm{mV} / \mathrm{m}$ during the most intensive period of the geomagnetic storm accompanying the SPE. The temperature increase due to Joule and particle heating was calculated, taking into account radiative cooling. The temperature increase at PMSE heights was found to be very small.

The observed PMSE were rather intensive and extended over the 80-90 km height interval. PMSE almost disappeared above $86 \mathrm{~km}$ at the time of greatest Joule heating on 15 July 2000. Neither ionisation changes, nor Joule/particle heating can explain the PMSE reduction. Transport effects due to the strong electric field are a more likely explanation.
\end{abstract}

Key words. Meteorology and atmospheric dynamics (middle atmospheric dynamics), ionosphere (ionospheric disturbances; solar radiation and cosmic ray effects)

\section{Introduction}

Solar proton events (SPE) are characterized by intensive particle precipitation, mostly protons of energies from 10$300 \mathrm{MeV}$ (Brasseur and Solomon, 1986). These events may increase ionisation in the upper mesosphere to high levels and are often also associated with magnetospheric distur-

Correspondence to: V. Barabash

(victoria@irf.se) bances leading to Joule heating of the neutral upper atmosphere in the polar regions (Roble et al., 1987). The ionisation gives rise to chemical reactions and changes in the densities of active atmospheric constituents. Amongst other effects, this causes a depletion of ozone in the middle atmosphere, thus reducing the radiative heating rate in the upper stratosphere and mesosphere (Johnson and Luhmann, 1993).

The SPE, which occurred on 14-16 July 2000, was the third largest solar event in the past 30 years (Jackman et al., 2001). It causes increased production of $\mathrm{HO}_{\mathrm{x}}\left(\mathrm{H}, \mathrm{HO}, \mathrm{HO}_{2}\right)$ and $\mathrm{NO}_{\mathrm{x}}\left(\mathrm{N}, \mathrm{NO}, \mathrm{NO}_{2}\right)$ in the mesosphere and the upper stratosphere. Measurements from the UARS HALOE and NOAA 14 SBUV/2 instruments indicated a short-term (day) middle mesospheric ozone depletion of $70 \%$ caused by $\mathrm{HO}_{\mathrm{x}}$ and a long-term (several days) upper stratospheric ozone depletion of $9 \%$ caused by $\mathrm{NO}_{\mathrm{x}}$ (Jackman et al., 2001). The results of Reagan et al. (1981) suggested that, although the mesospheric ozone depletion lasts a relatively short period, it produces a long-term decrease in the neutral heating rate that causes a reduction of mesospheric temperatures during several days after the event. The Joule heating, on the other hand, produces a sudden increase in the neutral heating rate in the upper mesosphere and lower thermosphere (Reagan et al., 1981; Roble et al., 1987). The latter observations have been found to be consistent with model predictions by Johnson (1987), who also emphasized the possibility of enhanced diurnal tidal amplitudes when a Joule heat source is added in the $80-120 \mathrm{~km}$ altitude range. That the latter can indeed occur has been confirmed by observations made by the Poker Flat, Alaska, and MST radar during SPEs in 1982 and 1984 (Johnson and Luhmann, 1993). Thus, the SPE represents a dramatic change in ionospheric and atmospheric conditions in the D- and E-regions, and, therefore, might have an impact on the middle atmosphere and subsequently Polar Mesospheric Summer Echoes (PMSE) (Röttger, 1997).

PMSE are strong, coherent radar echoes registered by VHF radars at $80-90 \mathrm{~km}$ altitude in the summer months at high latitudes (Ecklund and Balsley, 1981; Röttger et al., 1988) and mid-latitudes (Czechowsky et al., 1979, Reid et 


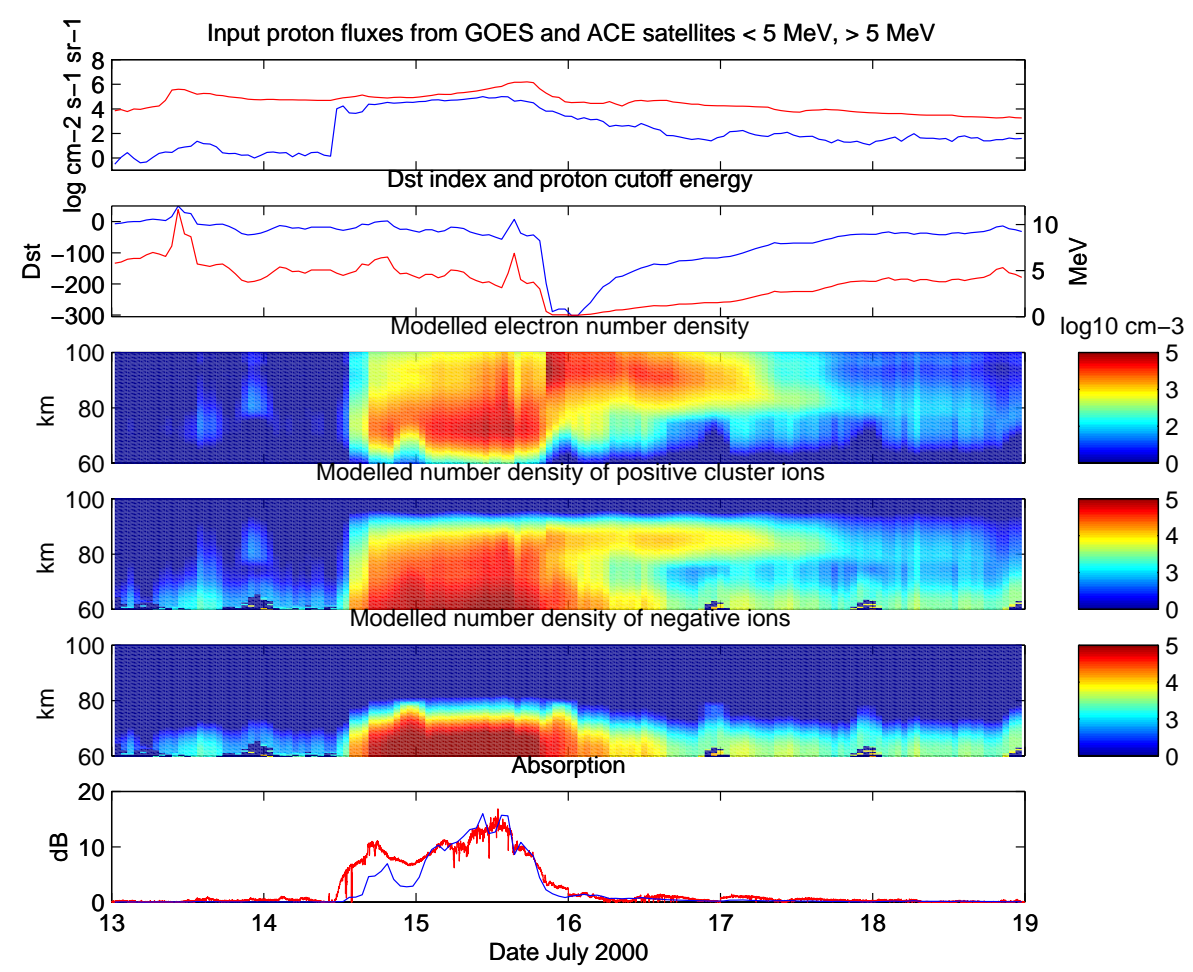

Fig. 1. The model results for 14-16 July 2000. Top panel: Solar proton fluxes from GOES 10 satellite: red- $<5 \mathrm{MeV}$, blue- $>5 \mathrm{MeV}$. 2 nd panel: Dst index (blue) and proton cutoff energy (red). 3rd-5th panels: modelled densities of electrons, positive cluster ions and negative ions. Colour scale shows $\log$ density $\mathrm{cm}^{-3}$. 6th panel: cosmic noise absorption at $30 \mathrm{MHz}$ calculated from the model results (blue) and measured (red) by a riometer in Kilpisjärvi.

al., 1989; Thomas et al., 1992; Chilson et al., 1997). A precondition for the echoes is the presence of structures in the electron density on the scale of the radar half wavelength. It is generally considered that this can occur only if charged aerosols are present. Overviews of PMSE are given by Cho and Kelly (1993) and Cho and Röttger (1997).

There are rather few studies concerning the possible effects of SPE on PMSE, or on the closely related polar mesospheric clouds (PMC) and noctilucent clouds (NLC). Von Zahn (2001) pointed out that on 14 July, the ALOMAR lidar located in Northern Norway $\left(69^{\circ} \mathrm{N}, 16^{\circ} \mathrm{E}\right)$ observed an aerosol layer above $85 \mathrm{~km}$, that is likely to be noctilucent clouds (NLC). Rapp et al. (2002) investigated the dependence of PMSE on the modelled background electron number density in the presence of the SPE on 14-16 July 2000. A significant, negative correlation between SNR (signaltonoise-ratio) and the electron number density for densities on the order of $10^{5} \mathrm{~cm}^{-3}$ was found. Rapp et al. (2002) explained the anticorrelation as due to a limited amount of aerosol particles.

This study presents PMSE measurements made by the 52 $\mathrm{MHz}$ MST radar (ESRAD) located at Esrange $\left(67^{\circ} 53^{\prime} \mathrm{N}\right.$, $21^{\circ} 06^{\prime} \mathrm{E}$ ) in Northern Sweden during the SPE on 14-16 July 2000. Because of the long duration of the SPE (several days) it is possible to model the electron and ion number densities during day and night conditions, using the observed proton fluxes and, to combine this with an empirical model for elec- tron density due to solar illumination. The high densities of electrons and ions achieved during the SPE allow us to test whether PMSE strength is related to the density of free electrons or to something else. The temperature changes in the lower thermosphere due to Joule and particle heating have been calculated.

\section{Proton fluxes, energetic particle precipitation, elec- tron and ion number densities}

The solar protons were measured by the NOAA GOES10 (http://sec.noaa.gov/ftpmenu/lists/particle.html) and ACE (http://sec.noaa.gov/ace/) satellites, for energies above and below $5 \mathrm{MeV}$, respectively. The proton fluxes for $<5 \mathrm{MeV}$ and $>5 \mathrm{MeV}$ are shown in the top panel of Fig. 1. The sharp increase of the high-energy proton fluxes intensities starts at about 10:45 UT on 14 July. It remains rather stable during 14 and 15 July, gains its maximum at 12:30 UT on 15 July (NOAA Space Environment Services Centre) and begins to decrease first abruptly and then more slowly, after 20:00 UT on 15 July.

Two separate exponentials (one below $5 \mathrm{MeV}$ and one above $5 \mathrm{MeV}$ ) have been found to give the best fit to the joint differential flux measurements from ACE and GOES satellites. It should be pointed out that, in most solar proton events, low energy protons, i.e. below $5 \mathrm{MeV}$, never reach the 


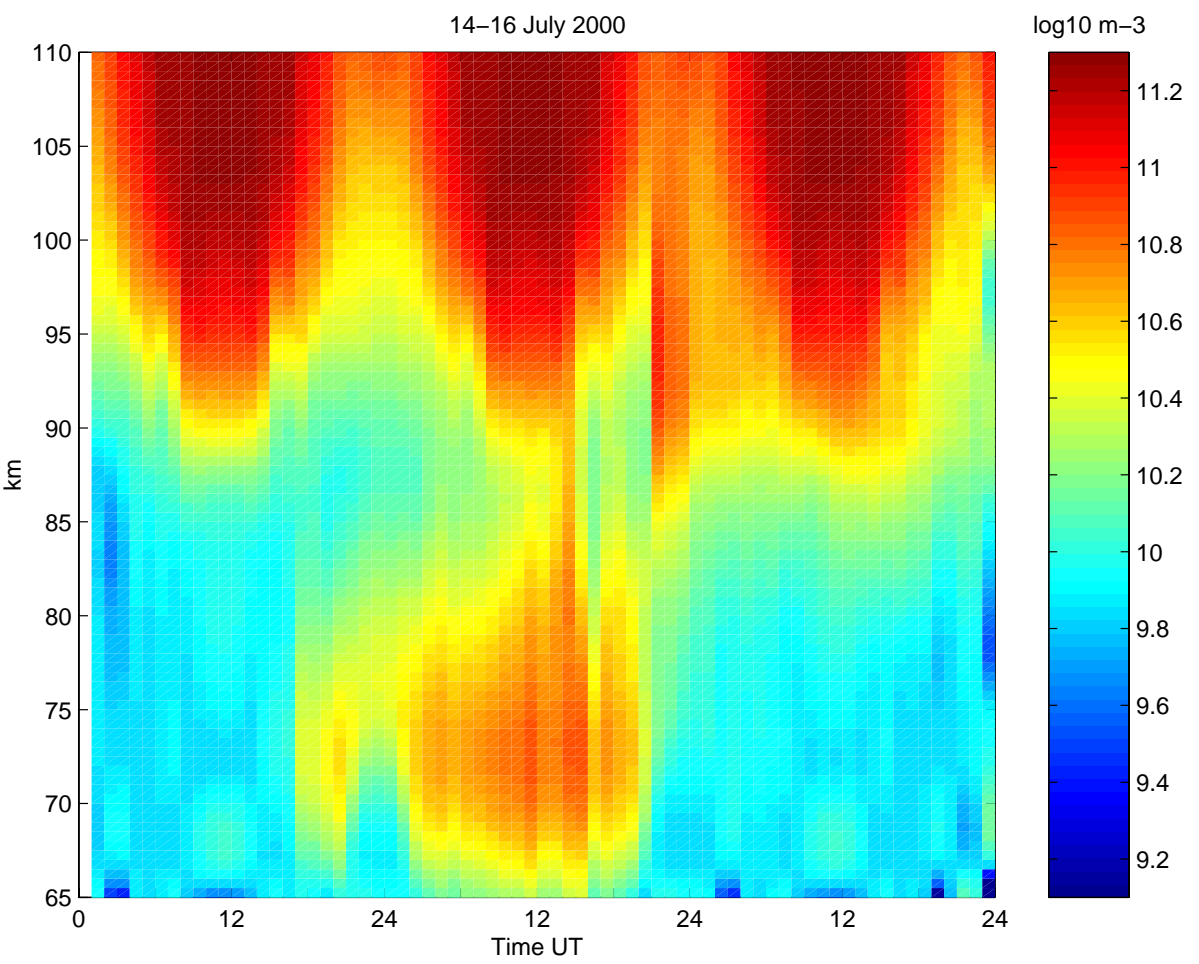

Fig. 2. Total electron number density from 14-16 July 2000.

atmosphere at the geomagnetic latitude of our radar observations $\left(65^{\circ} \mathrm{N}\right)$, because of shielding by the Earth's magnetic field. However, lower-energy protons, as low as $0.1 \mathrm{MeV}$, can be expected to reach the atmosphere at our site during the major storm which immediately followed the period of most intense proton fluxes, starting at about 20:00 UT on 15 July. We have used the results of Smart et al. (1999a, b, c) to calculate the proton cutoff energy as a function of the Dst index (the latter from the World Data Centre for Geomagnetism, Kyoto, Japan). We have fitted an analytical form,

Ecut $=10 .\left(0.7997+0.0053^{*}\right.$ Dst $)$

to the tables and figures in these papers. The predicted cutoff energy (Ecut) during the SPE, calculated using the Dst index, is shown in Fig. 1. The resultant electron and ion densities are shown in the colour panels in Fig. 1. The main part of the SPE produces ionisation below $80 \mathrm{~km}$, with the peak electron densities around $70 \mathrm{~km}$ altitude.

The obtained spectrum has been used as an input to the energy deposition/ion-chemical model to estimate the density of free electrons and ions in the upper atmosphere (Kirkwood and Osepian, 1995). The ion chemistry calculations include molecular ions $\left(\mathrm{NO}^{+}, \mathrm{O}_{2}^{+}\right.$), positive cluster ions (clusters of $\mathrm{NO}^{+}$and $\mathrm{O}_{2}^{+}$with $\mathrm{O}_{2}, \mathrm{~N}_{2}, \mathrm{CO}_{2}, \mathrm{H}_{2} \mathrm{O}$ and proton hydrates) and negative ions $\left(\mathrm{O}_{2}^{-}\right.$and heavy negative ions $\mathrm{CO}_{3}^{-}$ and $\mathrm{NO}_{3}^{-}$).

The electron number density due to solar ionization has been taken from a statistical study of electron densities due to solar radiation in the E-region, i.e. above $90 \mathrm{~km}$ (Kirkwood, 1993) (Fig. 2). The diurnal variations in the negative ion and electron number densities are due to the fact that the negative ions are more persistent during the night, as well as the increased attachment of electrons to form negative ions. During the daytime, the electrons are readily removed from the negative ions by sunlight and by reactions with atomic oxygen. The daily variation of the positive cluster ions is due to the reduction in recombination at night as the number of free electrons is diminished. The calculations show higher electron densities above ca. $80 \mathrm{~km}$ for ca. $36 \mathrm{~h}$, starting from 20:00 UT on 15 July when the Dst index drops sharply and remains at values of -300 to -100 . In these conditions, lower energy protons are expected to reach the atmosphere. The lowest panel of Fig. 1 shows the observed absorption of cosmic radio noise at $30 \mathrm{MHz}$ measured by the Imaging Riometer for Ionospheric Studies (IRIS) in Kilpisjärvi $\left(69^{\circ} 30^{\prime} \mathrm{N}, 20^{\circ} 47^{\prime} \mathrm{E}\right)$. The riometer absorption level reaches as high as $18 \mathrm{~dB}$ during the SPE. Comparison between the measured absorption and the modelled values indicates that the model represents the situation in the atmosphere reasonably well, although there is some discrepancy in the early part of the event. This is likely due to the extremely high proton energies present at the start of the event, which produce ionisation below $50 \mathrm{~km}$ altitude, beyond the limit of our model.

\section{Characteristics of PMSE}

The MST radar ESRAD $\left(67^{\circ} 53^{\prime} \mathrm{N}, 21^{\circ} 06^{\prime} \mathrm{E}\right)$ operates at $52 \mathrm{MHz}$ with $72 \mathrm{~kW}$ peak power and a maximum duty cycle of $5 \%$. The antenna consists of a $12 \times 12$ array of 5-element 

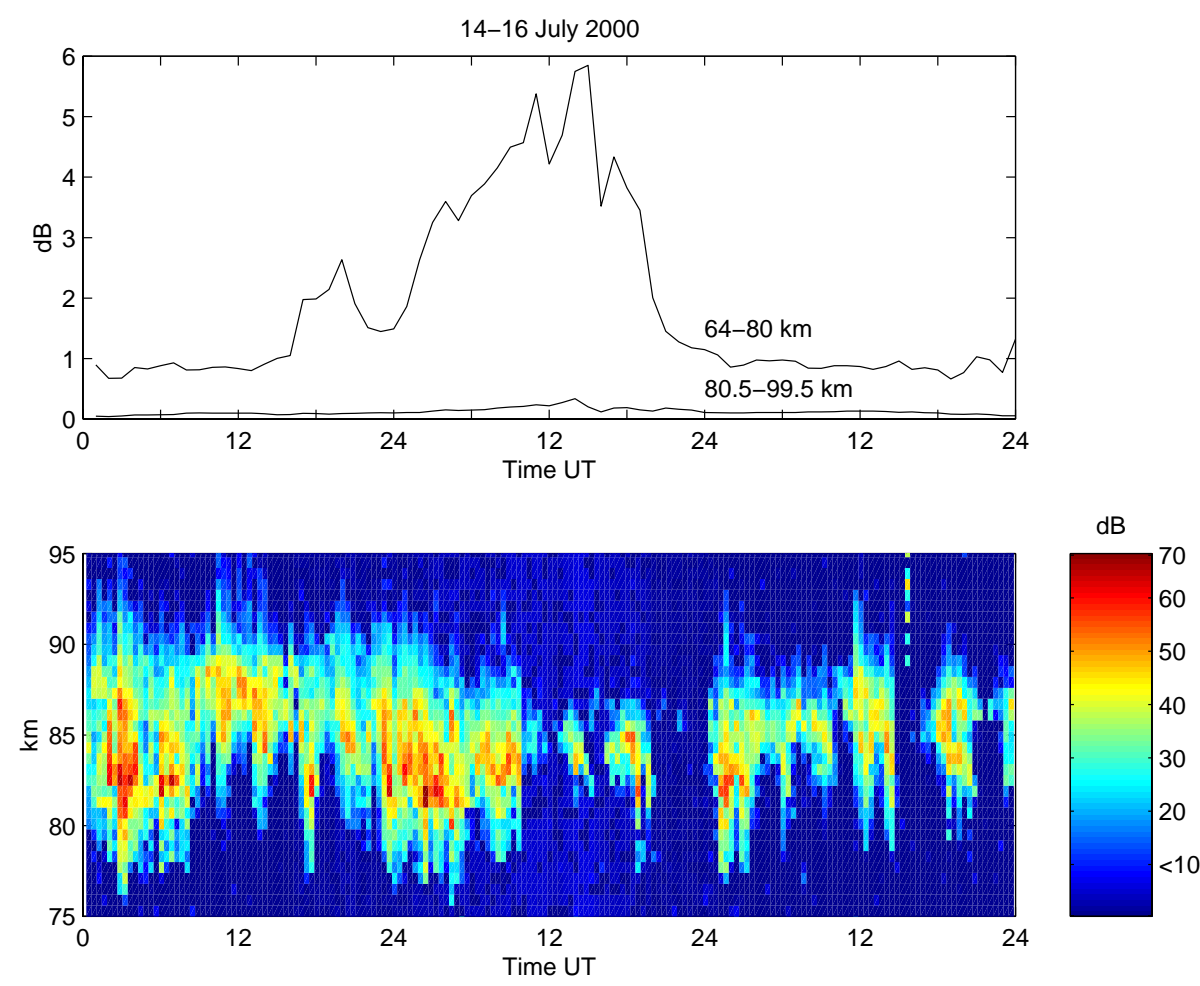

Fig. 3. Top panel: Height integrated absorption of the radar signal at $52 \mathrm{MHz}$. Bottom panel: Corrected ESRAD echo power.

Yagis with a $0.7 \lambda$ spacing. The radar was operated in two modes. For the altitude range of $80-90 \mathrm{~km}$ data were collected using a 16-bit complementary code with a $150 \mathrm{~m}$ range resolution. The sampling frequency was set to $1450 \mathrm{~Hz}$. For the altitude range of 4.8-99.6 km a 8-bit complementary code with a $600-\mathrm{m}$ range resolution was used. The sampling frequency for that mode was set to $1300 \mathrm{~Hz}$.

Echoes have been judged to be present if the SNR (signalto-noise ratio) exceeded $-10 \mathrm{~dB}$. However, to allow us to eliminate the effects of background (cosmic) noise variations, we generally use the radar signal power instead of SNR. For altitudes of $80-90 \mathrm{~km}$ the signal power has been median filtered with a time resolution of $15 \mathrm{~min}$. To take into account absorption of the radar signal by ionisation produced by the energetic particles in the atmosphere below $80 \mathrm{~km}$ during the solar proton event, the signal power $\sigma$ has been corrected according to:

$\sigma=s_{\text {radar }}+2 A$,

where $s_{\text {radar }}$ is the MST radar observed backscatter signal power, $\mathrm{dB}, A$ is the height integrated absorption of the radar signal at $52 \mathrm{MHz}$ between $64-80 \mathrm{~km}, \mathrm{~dB}$.

Height integrated absorption of the radar signal at $52 \mathrm{MHz}$ has been estimated using the modeled electron number densities (Kirkwood and Osepian, 1995) and the classical equation (Hargreaves, 1992):

$A=4.5 \cdot 10^{-5} \int \frac{N_{e} \cdot v_{e n}}{\omega^{2}+v_{e n}^{2}} d x$
$N_{e}=\left(N_{e}^{2} \text { (protons) }+N_{e}^{2}(\text { sun })\right)^{\frac{1}{2}}$, where $N_{e}$ is the total electron number density, $\mathrm{m}^{-3}$,

$N_{e}$ (protons) is the modelled electron number density due to the solar proton event, $\mathrm{m}^{-3}$,

$N_{e}$ (Sun) is the electron number density due to the sunlight, $\mathrm{m}^{-3}$ (Kirkwood, 1993),

$v_{e n}$ is the electron-neutral collision frequency, $\mathrm{s}^{-1}$, $\omega$ is the angular wave frequency, $\mathrm{s}^{-1}$.

Height integrated absorption of the radar signal at $52 \mathrm{MHz}$ between $80-99.5 \mathrm{~km}$ is very small and not taken into consideration (Fig. 3). Since the transmitted radar signal is absorbed twice, the height-integrated absorption is multiplied by a factor of 2 in Eq. (2). Faraday rotation effects calculated according to Kirkwood and Röttger (1995) are found to be negligible in the entire height range.

As it can be seen, PMSE is rather intensive and extends over the whole height interval between 80 and $90 \mathrm{~km}$, i.e. the limits where they have been mainly observed (Fig. 3). Comparison of the radar signal height profiles with the total electron number density demonstrates their strong altitude dependence (Fig. 4) and reveals a decrease in the radar signal above $86 \mathrm{~km}$ during the strong ionospheric disturbances on 15 July. More exact comparison of this decrease in PMSE on 15 July with the ionospheric disturbance is the main aim of this paper. However, since fluctuations of the radar signal at those heights are quite common, they are not necessarily connected to the SPE. Above $90 \mathrm{~km}$ the electron number density is mainly determined by the ionization from the Sun and is modified only slightly by the SPE. 

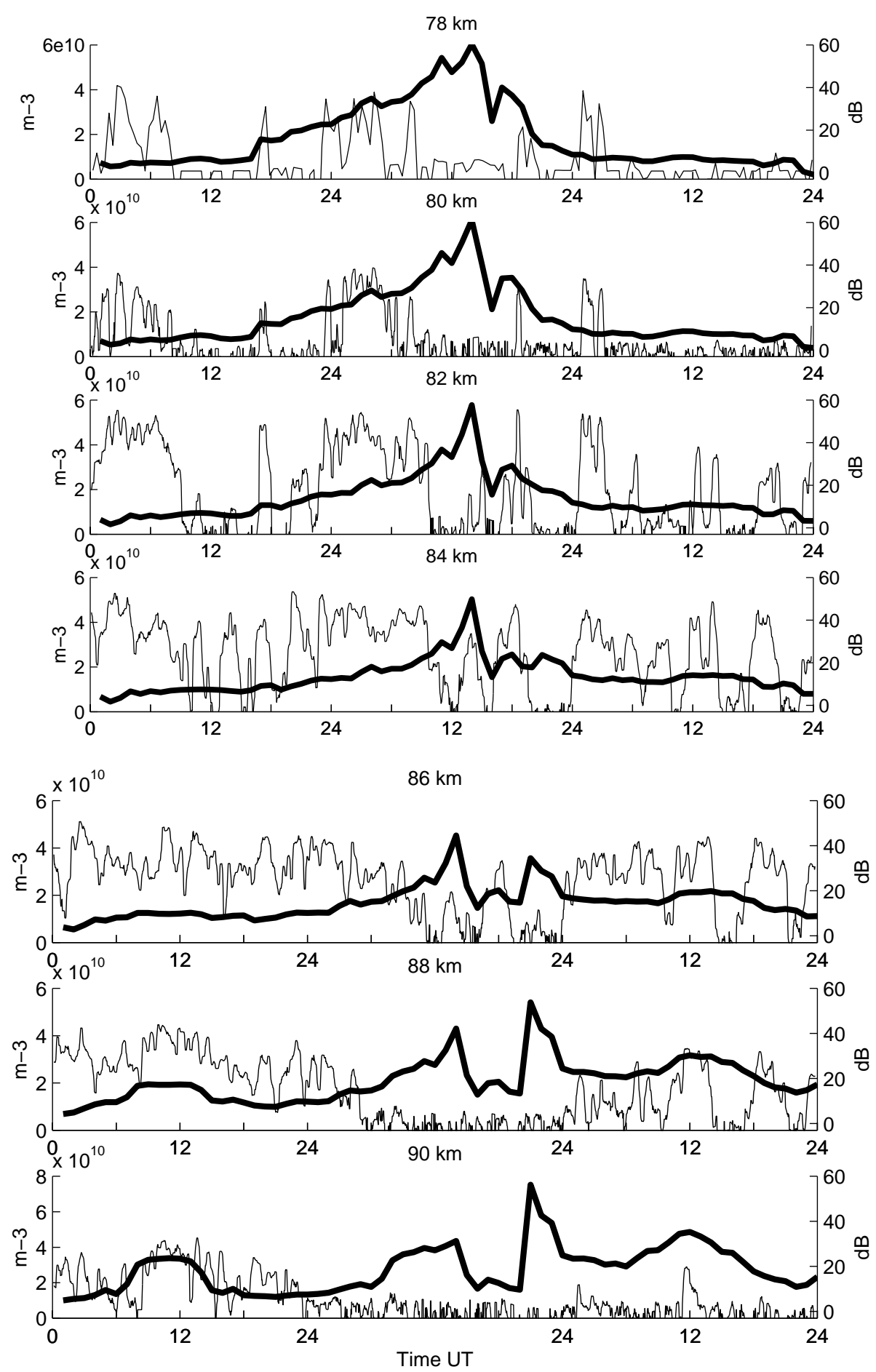

Fig. 4. Combined plots of the electron number density (bold line) and the ESRAD echo power (normal line) for different altitudes. 



Fig. 5. Top panel: Height integrated Hall conductivity. Bottom panel: Specific Pedersen conductivity.

\section{Calculation of conductivities and electric field}

The ion-neutral and electron-neutral collision frequencies have been calculated from the MSISE-90 thermospheric model, which provides estimates of the temperature of the atmosphere and of the number density of several prevalent species. It uses the $10.7 \mathrm{~cm}$ solar radio flux and the Ap geomagnetic indices as input. Those parameters have been obtained from the World Data Centre for Geomagnetism in Kyoto, Japan. The $10.7 \mathrm{~cm}$ solar radio flux was taken as $210 \mathrm{~W} / \mathrm{m}^{2} / \mathrm{Hz}$ for $14 \mathrm{July}, 220.1 \mathrm{~W} / \mathrm{m}^{2} / \mathrm{Hz}$ for $15 \mathrm{July}$, $226.1 \mathrm{~W} / \mathrm{m}^{2} / \mathrm{Hz}$ for $16 \mathrm{July}$. The Ap index reached 154 on 14 July and 400 on 15 July. Pedersen and Hall conductivities have been calculated according to the equation (Kirkwood et al., 1988):

$$
\begin{aligned}
\sigma_{p} & =\frac{N_{e} \cdot q}{B}\left(\frac{\omega_{i} \cdot v_{i n}}{\omega_{i}^{2}+v_{i n}^{2}}+\frac{\omega_{e} \cdot v_{e n}}{\omega_{e}^{2}+v_{e n}^{2}}\right) \\
\sigma_{H} & =\frac{N_{e} \cdot q}{B}\left(\frac{\omega_{i}^{2}}{\omega_{i}^{2}+v_{i m}^{2}}-\frac{\omega_{e}^{2}}{\omega_{e}^{2}+v_{e n}^{2}}\right) \\
N_{e} & =\left(N_{e}^{2} \text { (protons) }+N_{e}^{2}(\text { sun })\right)^{\frac{1}{2}}
\end{aligned}
$$

$N_{e}$ is the total electron number density, $\mathrm{m}^{-3}$,

$N_{e}$ (protons) is the modelled electron number density due to the solar proton event, $\mathrm{m}^{-3}$,

$N_{e}$ (Sun) is the electron number density due to the sunlight, $\mathrm{m}^{-3}$ (Kirkwood, 1993),

$q$ is the electron charge, $C$,

$B$ is the magnetic field strength, taken as $5.05 \cdot 10^{-5} \mathrm{~T}$,

$v_{i n}$ is the ion-neutral collision frequency, $\mathrm{s}^{-1}$,

$v_{e n}$ is the electron-neutral collision frequency, $\mathrm{s}^{-1}$,

$\omega_{i}$ is the ion gyrofrequency, $\mathrm{rad} \cdot \mathrm{s}^{-1}$, and

$\omega_{e}$ is the electron gyrofrequency, $\mathrm{rad} \cdot \mathrm{s}^{-1}$.

Height-integrated conductivity $\sum h$ has been calculated by integrating over the altitude interval $50-150 \mathrm{~km}$. The daily variations of the integrated Hall and the specific Pedersen conductivities are in good correlation with the electron number density due to sunlight, i.e. gaining their maxima at about 11:00 UT (local solar noon is 10:40 UT) (Fig. 5). The second, less pronounced maximum between $71-73 \mathrm{~km}$, seen in the specific Pedersen conductivity, corresponds to the increased electron number density due to the solar proton event.

To calculate the ionospheric electric field (assumed perpendicular to the Earth's magnetic field which has an inclination of $77^{\circ} 8^{\prime}$ for Kiruna) in the north-south direction $E x$, the usual dominant direction, the equation for the magnetic 

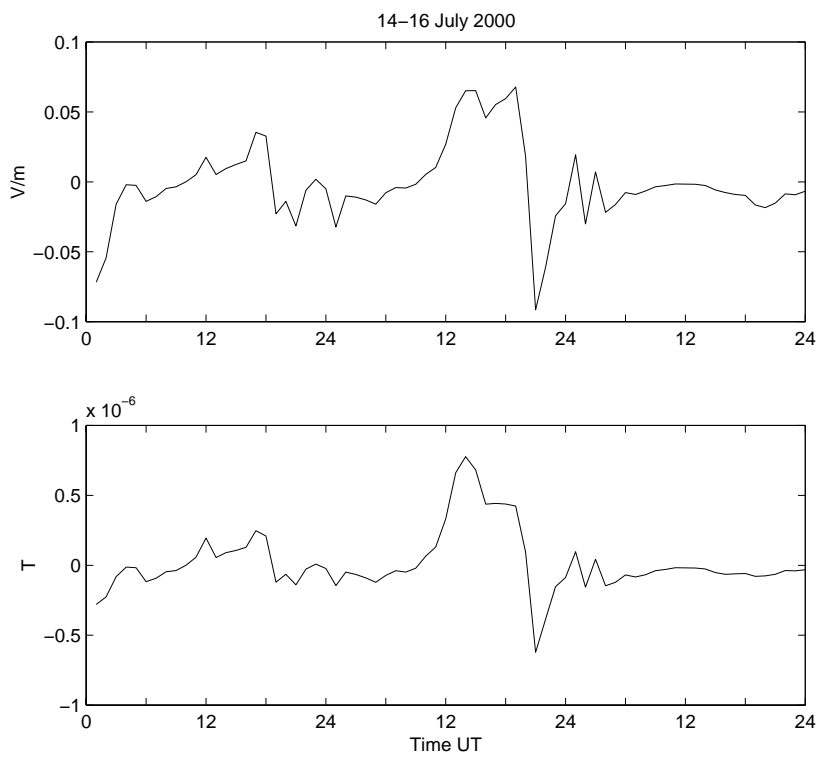

Fig. 6. Top panel: The northward component of the ionospheric electric field. Bottom panel: The deflection of the northward component of the magnetic field measured by the magnetometer in Kiruna.

field $B$, induced by an infinitely long slab with width $a$ and linear current density $j$ has been used:

$B=\frac{\mu \cdot j}{\pi} \arctan \left(\frac{a}{2 R}\right)$,

where $\mu$ is $4 \pi \cdot 10^{-7} \mathrm{~N} / \mathrm{m}, R$ is a distance from the slab. Since the area affected by the SPE comprises the entire polar cap and extends many hundreds of kilometres south of the observation site, $a$ is much larger than $R$, and the expression can be simplified to:

$B=\frac{\mu \cdot j}{2}$,

where $B$ is the deflection of the northward component of the magnetic field. This was measured by the flux-gate magnetometer (with 20-s time resolution) in Kiruna $\left(67^{\circ} 54^{\prime} \mathrm{N}\right.$, $20^{\circ} 24^{\prime} \mathrm{E}$ ) (Fig. 6). The magnetosphere electric field of large scale $(100 \mathrm{~km})$ can penetrate well below the ionosphere and all the way down to $20-40 \mathrm{~km}$ (Brekke, 1997) and remains constant over the considered altitude range (Kelley, 1989). This mapping of the electric field is expected theoretically, due to high conductivity along the magnetic field lines. It is also confirmed in experimental results by Mozer and Serlin (1969), who detected the electric fields at $30 \mathrm{~km}$ altitude.

The linear current density is:

$j=\sum h \cdot E x$.

The northward component of the electric field is, therefore:

$E x=\frac{2 \cdot B}{\mu \cdot \sum h}$.

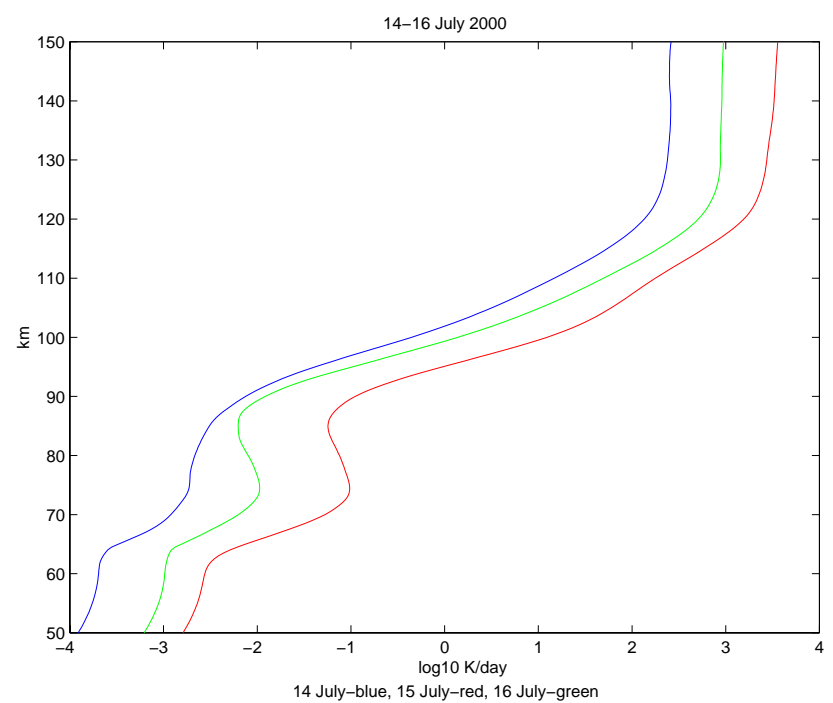

Fig. 7. Daily net Joule heating rates.

As is seen (Fig. 6), the largest electric field up to $91 \mathrm{mV} / \mathrm{m}$ is calculated to have appeared during the most intense geomagnetic disturbance, as indicated by both the local magnetometer data and the general Ap index.

Our assumption of an infinitely broad current sheet can lead to an underestimate of the ionospheric current and the associated electric field. On the other hand, our neglect of induced currents below the Earth's surface will lead to an overestimate. The relationship between ionospheric currents and magnetic disturbances at the Earth's surface in the auroral zone has been discussed in detail by Araki et al. (1989). For a current sheet with a north-south width of $800 \mathrm{~km}$, and a variation of $10 \mathrm{~s}$, they found on theoretical grounds that the infinite-current sheet assumption would lead to a $15 \%$ underestimate of the current, while neglecting the induced currents would lead to a $20 \%$ overestimate. Summarizing published observations of both ionospheric currents and ground magnetic disturbances in the auroral zone, they found that application of Eq. (8) could lead to between $60 \%$ underestimates and $20 \%$ overestimates of the ionospheric currents, on different occasions.

Additionally, the electric field might be overestimated due to the uncertainties in determining the Hall conductivity, which depends primarily on the accuracy of the electron density calculations. Since auroral precipitation (i.e. electrons with $\mathrm{keV}$ energies from within the magnetosphere), due to a lack of relevant data could not be taken into consideration in the energy deposition/ion-chemical model, we should remember that the Hall conductivity might be underestimated particularly close to magnetic midnight (21:30 UT), when aurora are common. 




Fig. 8. Daily net particle heating rates.

\section{Joule and particle heating}

The electric field is a potential heat source for ionospheric particles (Rees, 1989). It is due to the fact that, under the action of the electric field, charged particles drift relative to one another and to neutral particles. Collisions between the particles limit their drift and convert part of the drift energy into the thermal energy. Since this Joule heating is due to the Pedersen current (Rees et al., 1983), the equation for the heating $P$ will be:

$P=\sigma_{p} \cdot E_{x}^{2}$.

The local Joule heating rate is shown in Fig. 7. It gains maximum values at about $73 \mathrm{~km}$ and above $90 \mathrm{~km}$. The highest heating rate corresponds to the highest electric field on 15 July. However, even then the rate becomes competitive and dominates the solar heating rate of $3 \mathrm{~K} /$ day in the sunlit mesopause (Roble et al., 1987) only above $90 \mathrm{~km}$.

To calculate the particle heating rate the ionization rate from the energy deposition/ion-chemical model has been used (Kirkwood and Osepian, 1995) (Fig. 8). The particle heating rate is proportional to the ionization rate and, so follows the same altitude profile. This heating rate has a tendency to be the highest during the most intense geomagnetic disturbance 15 July. Note that our neglect of possible auroral precipitation means the Joule heating may be overestimated.

\section{Radiative heating and cooling}

The middle atmospheric cooling due to thermal radiation is mainly affected by the ro-vibrational bands of $\mathrm{CO}_{2}$ around $15 \mu \mathrm{m}$, by the $9.6 \mu \mathrm{m} \mathrm{O}_{3}$ ro-vibrational band and by the infrared (IR) $\mathrm{H}_{2} \mathrm{O}$ bands (dominated by the rotational band).

The radiative transfer in the $15 \mu \mathrm{m} \mathrm{CO}$ band provides the major contribution to the radiative cooling throughout the middle atmosphere. This is essentially the only radiative

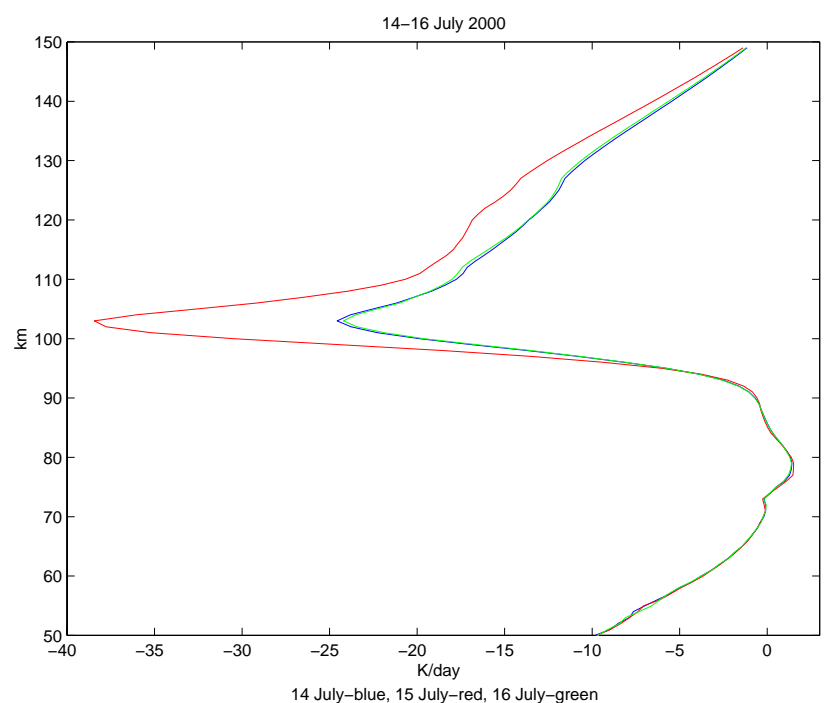

Fig. 9. Radiative cooling/heating rates of $\mathrm{CO}_{2}$.

mechanism of cooling in the upper mesosphere and lower thermosphere. The radiative cooling in the $9.6 \mu \mathrm{m} \mathrm{O} \mathrm{O}_{3}$ band is next in importance. Its effect is about $25 \%$ of the total cooling in and around the stratopause and decreases with altitude. The $\mathrm{H}_{2} \mathrm{O}$ bands play a tertiary role, contributing about $5-7 \%$ of the total IR cooling of the middle atmosphere.

In this study we confined our estimations of radiative cooling to that by the $\mathrm{CO}_{2}$ molecules (Fig. 9). In the altitude region above about $85 \mathrm{~km}$ the $\mathrm{CO}_{2}$ cooling is significantly affected by the non-local thermodynamic equilibrium (nonLTE). The ALI-ARMS (Kutepov et al., 1998; Gusev et al., 2002) code package was used for calculation of this cooling. The model of non-LTE in $\mathrm{CO}_{2}$ corresponds to that described by Shved et al. (1998). We accounted for 113 vibrational levels of $5 \mathrm{CO}_{2}$ isotopic species $(626,636,628,627$, and 638) and considered line-by-line radiative transfer in about 300 ro-vibrational bands (with total number of lines exceeding 30000 ) including those in the $1-5 \mu \mathrm{m}$ near-infrared spectral region. Therefore, the obtained cooling rates also account for heating effects due to the absorption of the near-infrared solar radiation. The spectroscopic data for all bands considered were taken from the spectral database HITRAN2000.

The atmospheric pressure and temperature distributions in the altitude region of $50-150 \mathrm{~km}$ as well as the volume mixing ratios for all atmospheric components except for $\mathrm{CO}_{2}$ were taken from MSISE-90 model for the corresponding days and times. For the $\mathrm{CO}_{2}$ volume mixing ratio (vmr) we used the newest data presented by Kaufmann et al. (2002). These data were retrieved from the $\mathrm{CO}_{2}$ limb radiances obtained in the CRISTA 1 and 2 satellite experiments (Offermann et al., 1999; Grossmann et al., 2002) and are significantly lower (up to 50\%) above the altitude of $70 \mathrm{~km}$ than those based on earlier rocket data (see Kaufmann et al., 2002 for the discussion). It is worth noticing here that the $\mathrm{CO}_{2}$ cooling rate at about $80 \mathrm{~km}$ is roughly proportional to the $\mathrm{CO}_{2}$ vmr. Therefore, the cooling calculated in this study 
for the CRISTA $\mathrm{CO}_{2} \mathrm{vmr}$ is up to $50 \%$ lower than that for the vmr based on the rocket measurements (Offermann and Grossmann, 1973; Philbrick et al., 1973; Trinks et al., 1978; Offermann et al.; 1981).

The $\mathrm{CO}_{2}$ non-LTE cooling in the mesosphere and lower thermosphere is strongly affected by the quenching rate of the $v_{2}$ vibrations of the $\mathrm{CO}_{2}$ molecules by collisions with the $\mathrm{O}\left({ }^{3} \mathrm{P}\right)$ atoms. This rate is defined by the product of the rate coefficient for the reaction $\mathrm{CO}_{2}\left(v_{2}\right)+\mathrm{O}\left({ }^{3} \mathrm{P}\right) \rightarrow \mathrm{CO}_{2}$ $\left(v_{2}-1\right)+\mathrm{O}\left({ }^{3} \mathrm{P}\right)$ and the $\mathrm{O}\left({ }^{3} \mathrm{P}\right)$ density. We used in our calculations the O (3P) density from MSISE-90 model and the rate coefficient of $3 \cdot 10^{-12} \mathrm{~cm}^{3} \cdot \mathrm{s}^{-1}$. The latter is median between the laboratory value of $1.5 \cdot 10^{-12} \mathrm{~cm}^{3} \cdot \mathrm{s}^{-1}$ of Shved et al. (1991) and the value of about $6 \cdot 10^{-12} \mathrm{~cm}^{3} \cdot \mathrm{s}^{-1}$, which was derived by Sharma and Wintersteiner (1990) from the analysis of the IR Earth's limb radiance observations. Again, as in the case with the $\mathrm{CO}_{2} \mathrm{vmr}$, the $\mathrm{CO}_{2}$ non-LTE cooling is roughly proportional to the rate constant. Therefore, it will be approximately a factor two lower or higher (for the same $\mathrm{O}\left({ }^{3} \mathrm{P}\right)$ density) when lower or higher rate coefficient values, respectively, are used.

The total heating in the upper atmosphere is also affected by the absorption of ultraviolet radiation by ozone in the Huggins and Hartley bands and by molecular oxygen in the Schumann-Runge continuum (Brasseur and Solomon, 1986). The mean heating rate determined by those components may vary significantly with latitude and season. For the summer conditions at the latitude of $67^{\circ} \mathrm{N}$ the rates can be estimated as a continuous increase from $8 \mathrm{~K} /$ day at about $80 \mathrm{~km}$ up to $30 \mathrm{~K} /$ day above $95 \mathrm{~km}$.

\section{Temperature}

In order to test whether Joule and particle heating can have influenced the PMSE we have estimated the temperature change due to these sources using the conductivities and electric fields shown in Figs. 5 and 6. The time constant for radiative relaxation has been estimated for each altitude between 60 and $15 \mathrm{~km}$ as a linear coefficient between the cooling/heating rate due to carbon dioxide and the maximum (minimum) temperatures in the model runs described in the previous section (Newtonian cooling approximation, e.g. Brasseur and Solomon, 1986) (Fig. 10). Radiative cooling of this type is assumed to be the dominant process counteracting the effects of the Joule and particle heating. The temperature enhancement during the SPE has been calculated by including the Newtonian cooling, Joule and particle heating rates (Fig. 11). The temperature started to increase in the lower thermosphere on 14 July. Then, during the most intense period of the ionospheric disturbances on 15 July, the temperature continued to increase in the thermosphere and slightly in the mesosphere. Since radiative relaxation times are of the order of several days (Fig. 10) those temperature changes are expected to be rather stable and last several days after the event.

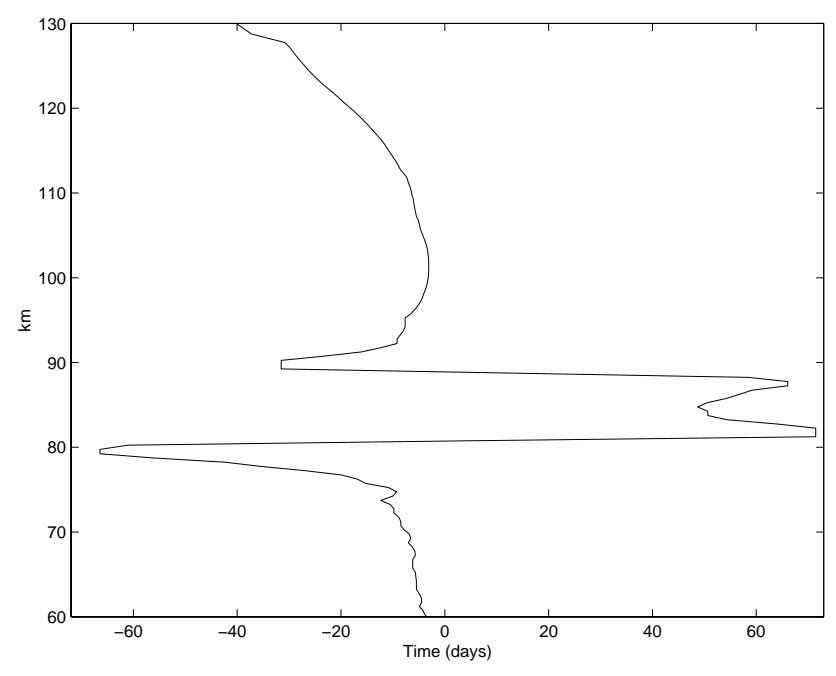

Fig. 10. Radiative relaxation time corresponding to cooling/heating rates of $\mathrm{CO}_{2}$ between $50-150 \mathrm{~km}$ altitude for 14-16 July 2000.

\section{Discussion}

During the SPE 14-16 July 2002 an enhanced energy flux has been transferred from the solar wind to the Earth's magnetosphere, thus, initiating a strong geomagnetic storm. The storm intensity can be illustrated by the Ap indices, which showed two maxima of 154 and 400 at 18:00 UT 14 July, and at 21:00 UT 15 July, respectively. That effect has also been confirmed by the magnetometer data from Kiruna, which demonstrated a significant deflection of the northward component of the magnetic field at the same time (Fig. 6). The geomagnetic storm enhances the ring current (see Dst index Fig. 1) and moves the magnetopause inward thus, reducing the proton cut-off rigidity (Hargreaves, 1992; Smart et al. 1999a, 1999b, 1999c) and allowing the lower-energy protons, as low as $0.1 \mathrm{MeV}$, to penetrate the atmosphere at the latitude of our site (magnetic latitude $65^{\circ} \mathrm{N}$ ). Moreover, towards the end of the storm it is likely that concentration of the auroral electrons will increase, particularly above $100 \mathrm{~km}$. Those electrons will increase the ionisation rate primarily in the auroral altitude interval (Roble et al., 1987) but not in the PMSE region. The ionisation rate due to solar protons maximized during the geomagnetic storm 15 July with a pronounced peak at $75-105 \mathrm{~km}$. When such enhanced ionization rate coincides with large electric fields increased Joule heating rates can be expected to occur.

Joule or frictional heating is produced by the electric field and its rate is equal to the total rate of mechanical energy input to the neutrals and the ions due to the collisions. Since the Joule heating rate is proportional to the height dependent Pedersen conductivity, the rate is equivalent to the altitude profile of that conductivity except for the factor of the squared electric field. Precipitated energetic protons greatly increased the Pedersen conductivity in the polar cap mesosphere. 


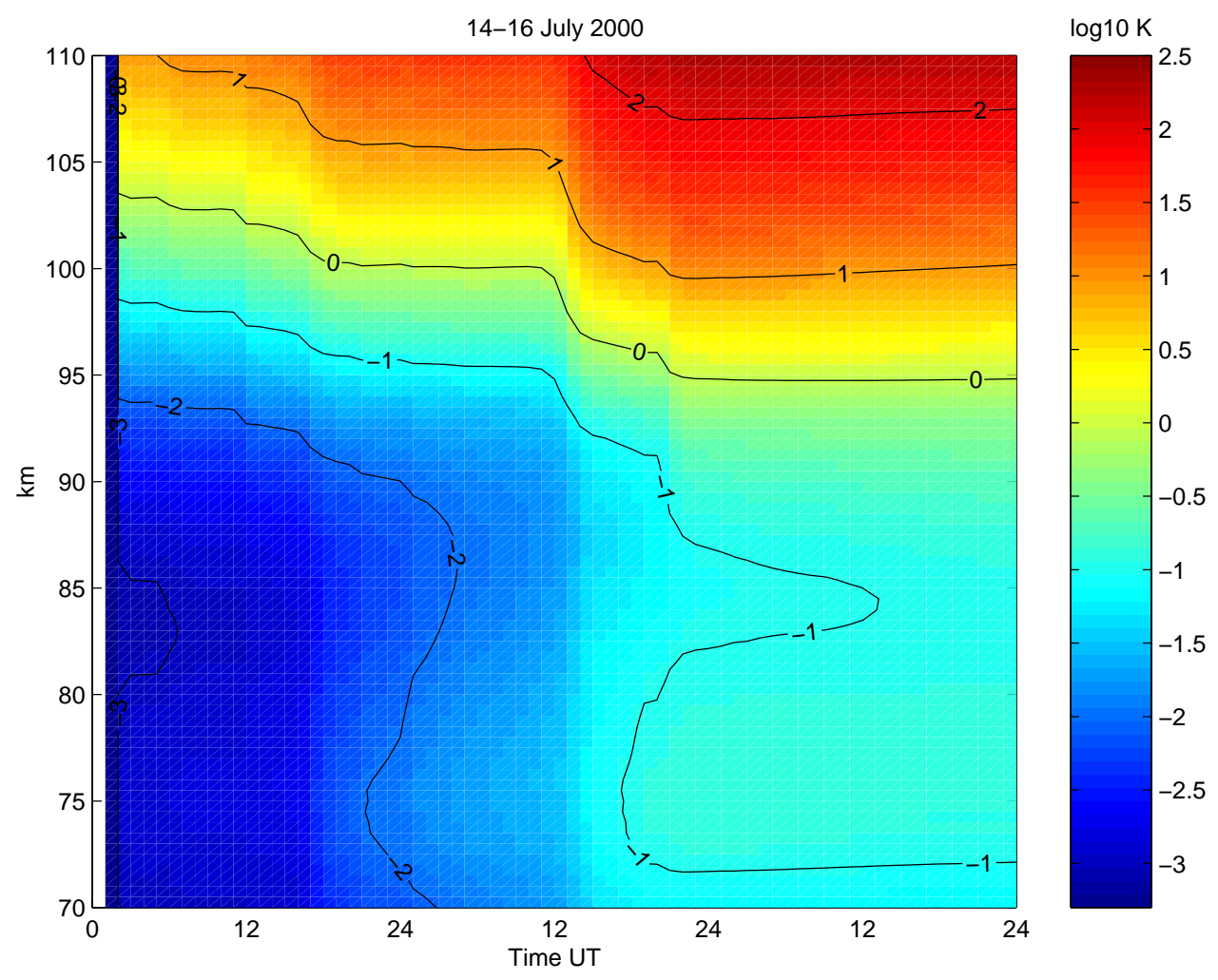

Fig. 11. Temperature enhancement between $70-110 \mathrm{~km}$ altitude due to Joule and particle heating.

Temperature changes calculated for the $70-110 \mathrm{~km}$ altitude range on the base of Joule and particle heating rates follow essentially the same time variability as the electric (and magnetic) fields, i.e. the temperature starts to increase when the fields start to deflect. Moreover, the values of the temperature change are very height dependent. A significant increase in the temperature on 15 July above $100 \mathrm{~km}$ is correlated in time with the decrease in the radar echo strength between $80-90 \mathrm{~km}$. However, the temperature change caused by Joule/particle heating at the height of the radar echoes is extremely small and does not exceed $0.1 \mathrm{~K}$. A previous study of the relation between mean daily temperature and mean daily occurrence of PMSE (Kirkwood et al., 2002) showed that some $10 \mathrm{~s}$ of $\mathrm{K}$ increase are needed to remove PMSE in normal summer conditions where it is well established, as here. The prevailing temperatures in these conditions lie well below those needed for saturation, at least during most of the day, due to the action of tides and gravity waves. Since the expected temperature increase is extremely small between $80-90 \mathrm{~km}$, orders of magnitude less than tidal and wave perturbations, the PMSE disappearance cannot be explained by the temperature change due to Joule heating.

Another factor that can influence the PMSE appearance is the particle motion in the ionosphere. The ion and particle motion in the high-latitude ionosphere is governed by electric fields, neutral winds, gravity and ambipolar diffusion (Kirkwood and von Zahn, 1991; Kirkwood and Nilsson, 2000). Assuming steady-state ion drift, plasma pressure gradients in the vertical direction and considering a single ion species, singly charged, the vertical component of the ion drift vector $\boldsymbol{v}_{\boldsymbol{i} z}$ (positive upwards) is:

$$
\begin{aligned}
& \boldsymbol{v}_{i z}=\frac{\omega_{i}^{2}}{\omega_{i}^{2}+v_{i}^{2}}\left(\frac{E_{E}}{B_{0}}-(+) W_{N} \sin I\right) \cos I \\
& +\frac{\omega v_{i}}{\omega_{i}^{2}+v_{i}^{2}}\left((-) \frac{E_{N}}{B_{0}}+W_{E}\right) \cos I \\
& +\left(1-\frac{\omega_{i}^{2}}{\omega_{i}^{2}+v_{i}^{2}} \cos ^{2} I\right) W_{z} \\
& -\frac{\omega_{e} \omega_{i}}{\omega_{e} v_{i}+\omega_{i} v_{e}}\left(\frac{1}{n_{i}} \frac{d\left(n_{i} k T\right)}{d z}+m g\right) . \\
& \cdot \frac{2}{q B_{0}}\left(\sin ^{2} I+\frac{v_{e} v_{i} \cos ^{2} I}{v_{e} v_{i}+\omega_{e} \omega_{i}}\right),
\end{aligned}
$$

$\omega_{i}, v_{i}$ are the ion gyro and collision frequencies,

$\omega_{i}, v_{e}$ are the electron gyro and collision frequencies,

$E_{E}, E_{N}$ are the northward and eastward components of the electric field perpendicular to the magnetic field $B_{0}$ directed downward (Northern Hemisphere),

$I$ is the inclination of the magnetic field $B_{0}$,

$W_{E}, W_{N}, W_{Z}$ are the horizontal (northward and eastward) and vertical (positive upwards) components of the neutral wind, 
$q$ is the electron charge,

$k$ is the Boltzmann constant,

$T$ is the plasma temperature (assumed equal for ions and electrons), and

$n_{i}$ is the ion density.

Signs in parentheses refer to the Southern Hemisphere where, keeping the convention that $v_{i z}$ is positive upwards, the sign of the wind term in Eq. (13a) is reversed, likewise the electric field term in Eq. (13b). The first term (13a) dominates above $120-130 \mathrm{~km}$, i.e. at heights where the ion gyro frequency exceeds the collision frequency and vertical motion is due to the motion along the magnetic field line following the component of the meridional wind in that direction, plus $\boldsymbol{E} \times \boldsymbol{B}$ drift due to east-west components of the electric field. The term (13b) dominates below $100-110 \mathrm{~km}$, i.e. at heights where the ion collision frequency exceeds the gyrofrequency. Here, the vertical motion is due to motion in the $\boldsymbol{W} \times \boldsymbol{B}$ direction resulting from the zonal wind, plus drift in the direction of the north-south component of the electric field. (Kirkwood and Nilsson, 2000). It should also be mentioned that a strong wind of $100 \mathrm{~m} / \mathrm{s}$ has the same effect as an electric field of $5 \mathrm{mV} / \mathrm{m}$. Thus, when the electric field is maximized, as in our case, the effect of neutral wind might be negligible. The term (13c) represents ion motion carried by the vertical component of the neutral wind, which may be significant at any height in the presence of strong vertical motion, for example, in atmospheric gravity waves. The term (13d) represents ion diffusion due to gradients in the plasma pressure and to the force of gravity (Kirkwood and Nilsson, 2000).

The Joule heating of neutrals can lead to upward neutral wind in a region of high electron densities and strong electric fields (Winser et al., 1986). As discussed by Kirkwood and von Zahn (1991), aerosol mobility at the relevant heights may be of the same order of magnitude as that for ions, especially if they are multiply charged. Extensive studies of ion and aerosol mobilities have been reported by Mason and McDaniel (1988), and Tammet (1995). At a height of $100 \mathrm{~km}$ a $40 \mathrm{mV} / \mathrm{m}$ electric field gives a drift velocity of $17 \mathrm{~m} / \mathrm{s}$ for particles with radii of $0.65 \mathrm{~nm}$, and $4 \mathrm{~m} / \mathrm{s}$ for particles with radii of $1.3 \mathrm{~nm}$ (Kirkwood and von Zahn, 1991). So vertical transport by the action of the electric field or wind on the aerosols or water cluster ions might be expected (Kirkwood and Nilsson, 2000). Those processes could result in a lack of charged aerosols to support the balance between the electron density inhomogeneity generation and diffusion necessary for VHF radar scatter to take place (Cho and Röttger, 1997). If so, the decrease in the radar echoes above $86 \mathrm{~km}$ on $15 \mathrm{July}$, when the electric field gains its maximum, might be connected to such transport.

We note that the first reduction of PMSE between 12:00 UT and 17:00 UT coincides with strong northward electric fields. This would drive positive ions/aerosols upward and negative aerosols downward. Removal of positive water-cluster ions from the top of the PMSE layer and negative aerosols from the bottom could account for the observed behaviour of the PMSE layer (where only a thin layer at 84$86 \mathrm{~km}$ remains). Aerosols moved to lower altitudes would evaporate, whereas cluster ions moved to higher altitudes would dissociate. The PMSE layer recovers briefly at 80 $84 \mathrm{~km}$ at the time when the electric field changes abruptly to southward, which could be due to the redistributing of the plasma components by the electric field, or to wave activity, which is common in PMSE. The second, almost $100 \%$ reduction in PMSE at all heights, between 19:00 UT and 24:00 UT, coincides with the time of the strong southward electric field. Such a field would drive negative aerosols upward and positive ions downward, again removing them from a height where they could survive, or contribute to PMSE, respectively. It should, however, be remembered that, even in normal conditions PMSE are often weak at this time of the day (Czechowsky et al., 1989; Kirkwood et al., 1995; Barabash et al., 1998). So it may be easier to remove them entirely with a small transport effect of the electric field.

\section{Conclusion}

The PMSE observed by ESRAD during the solar proton event on 14-16 July 2000 reveal a substantial decrease in the radar echoes above $86 \mathrm{~km}$ at the time of the greatest ionospheric disturbances on 15 July. The results of numerical simulations demonstrated an increase in electrons and ions number densities throughout the event. The electric field calculated on the basis of magnetometer measurements and modelled conductivities gains its maximum of $91 \mathrm{mV} / \mathrm{m}$ during the most intensive period of geomagnetic disturbances. The electric field is expected to produce upward/downward transport of ions and aerosols, thus, possibly decreasing the amount of charged aerosols in the vicinity of PMSE. The Joule heating generated by the geomagnetic storm might be responsible for the ion redistribution as well, through the generation of vertical winds. The temperature change due to Joule and particle heating at the PMSE height is far too little to lead to the destruction of the ice particles and PMSE disappearance, compared to the ever-present wave fluctuations. Since the temperature increase is extremely small between $80-90 \mathrm{~km}$ altitude, it is rather the transport effects due to the intensified electric field at the most disturbed time, which can be responsible for the reduction of PMSE above $86 \mathrm{~km}$.

Acknowledgements. We thank A. Osepian from the Polar Geophysical Institute, Murmansk, Russia for valuable discussions. We are indebted to personnel from the World Data Centre for Geomagnetism, Kyoto, Japan for providing geomagnetic data. Namely, M. Sugiura and T. Kamei for Dst index for year 2000, and Dst stations for final Dst index: Hermanus: South Africa, Kakoka: Japan, Honolulu: USA, San Juan: USA. We are also indebted to personnel from the NOAA Space Environment Services Centre, USA for data from GOES and ACE satellites, and to personnel from the Department of Communications Systems at Lancaster University, UK (http://www.dcs.lancs.ac.uk/iono/) and the Sodankylä Geophysical Observatory, Finland for providing the data from Imaging Riometer for Ionospheric Studies (IRIS). The IRIS station is funded by the Particle Physics and Astronomy Research Council (PPARC). 
Topical Editor U.-P. Hoppe thanks T. A. Blix and another referee for their help in evaluating this paper.

\section{References}

Araki, T., Schlegel, K., and Lühr, H.: Geomagnetic effects of the Hall and Pedersen currents flowing in the auroral ionosphere, J. Geophys. Res. 94, 17 185-17 199, 1989.

Barabash, V., Chilson, P., Kirkwood, S., Rechou, A., and Stebel, K.: Investigations of the possible relationship between PMSE and tides using a VHF MST radar, Geophys. Res. Lett., 25, 32973300, 1998.

Brasseur, G. and Solomon, S.: Aeronomy of the Middle Atmosphere, 2nd edition, D. Reidel Publishing Company, The Netherlands, 1986.

Brekke, A.: Physics of the upper polar atmosphere, Praxis Publishing Ltd., The White House, Eastergate, Chichester, West Sissex, PO20 6UR, UK, 1997.

Czechowsky, P., Rüster, R., and Schmidt, G.: Variations of mesospheric structures in different seasons, Geophys. Res. Lett., 6, 459-462, 1979.

Czechowsky, P., Reid, I.M., Rüster, R, and Schmidt, G.: VHF radar echoes observed in the summer and winter mesopause over Andöya, Norway, J. Geophys. Res., 94, 5199-5217, 1989.

Chilson, P. B., Czechowsky, P., Klostermeyer, J., Rüster, R., and Schmidt, G.: An investigations of measured temperature profiles and VHF mesosphere summer echoes at mid-latitudes, J. Geophys. Res., 102, 23 819-23 828, 1997.

Cho, J. Y. N. and Kelley, M. C.: Polar mesosphere summer radar echoes: Observations and current theories, Rev. Geophys., 31, 243-265, 1993

Cho, J. Y. N. and Röttger, J.: An updated review of polar mesosphere summer echoes: Observation, theory, and their relationship to noctilucent clouds and subvisible aerosols, J. Geophys. Res., 102, 2001-2020, 1997.

Ecklund, W. L. and Balsley, B. B.: Long-term observations of the arctic mesopause with the radar at Poker Flat, Alaska, J. Geophys. Res., 86, 7775-7780, 1981.

Grossmann, K. U., Offermann, D., Gusev, O., Oberheide, J., Riese M., and Spang, R.: The CRISTA-2 mission, J. Geophys. Res, 107, D23, 8173, 10.1029/2001JD000667, 2002.

Gusev, O. A. and Kutepov, A. A.: Non-LTE problem for molecular gas in planetary atmospheres, Stellar Atmosphere Modeling, edited by: Hubeny, I., Mihalas, D., and Werner, K., ASP Conference Series, 288, 2002, Proceedings of an international workshop, 8-12 April 2002, Tübingen, Germany, publ. SanFrancisco, 2002.

Hargreaves, J. K.: The solar-terrestrial environment, Cambridge University Press, 1992.

Jackman, C. H., McPeters, R. D., Labow, G. J., and Fleming, E. L.: Northern Hemisphere atmospheric effects due to the July 2000 solar proton event, Geophys. Res. Lett., 28, 15, 2883-2886, 2001.

Johnson, R. M.: PhD thesis, Department of Earth and Space Science, University of California at Los Angeles, 1987.

Johnson, R. M. and Luhmann, J. G.: Poker Flat MST radar observations of high latitude neutral winds at the mesopause during and after solar proton events, J. of Atm. and Terr. Phys., 55, 9, 1203-1218, 1993.

Kaufmann, M., Gusev, O. A., Grossmann, K. U, Roble, R. G., Hagan, M. E., Hartsough, C., and Kutepov, A. A.: The vertical and horizontal distribution of $\mathrm{CO}_{2}$ densities in the upper mesosphere and lower thermosphere as measured by CRISTA, J. Geophys. Res, 107, D23, 8182, 10.1029/2001JD000704, 2002.

Kelley, M.: The earth's ionosphere: plasma physics and electrodynamics, Academic Press Inc., 1989.

Kirkwood, S., Opgenoorth, H., and Murphree, J. S.: Ionospheric conductivities, electric fields and currents associated with auroral substrorms measured by the EISCAT radar, Planet. Space Sci., 36, 12, 1359-1380, 1988.

Kirkwood, S. and von Zahn U.: On the role of auroral electric fields in the formation of low-altitude sporadic-E and sudden sodium layers, J. Atm., Phys., 53, 389-407, 1991.

Kirkwood, S.: Modelling the undisturbed high-latitude E region, Adv. Space Res., 13, 3, 101-104, 1993.

Kirkwood, S. and Osepian, A.: Quantitative studies of energetic particle precipitation using incoherent-scatter radar, J. Geomagn. Geoelectr., 47, 783-799, 1995.

Kirkwood, S, and Röttger, J.: Faraday rotation affecting highlatitude MST VHF radar measurements, Proceedings of the Seventh Workshop on Technical and Scientific Aspects of MST Radar, Hilton Head Island, S. Carolina, USA, 1995.

Kirkwood, S., Cho, J., Hall, C., Hoppe, U.-P., Murtagh, D. P., Stegman, J., Swartz, W. E., van Eyken, A. P., Wannberg, G., and Witt, G.: A comparison of PMSE and other ground-based observations during the NLC-91 campaign, J. Atmos. And Terr. Phys., 57, 1, 35-44, 1995.

Kirkwood, S. and Nilsson, H.: High-latitude sporadic-E and other thin layers - the role of magnetospheric electric fields, Space Sci Rev., 91, 579-613, 2000.

Kirkwood, S., Barabash, V., Brändström, U., Moström, A., and Stebel, K.: Noctilucent clouds, PMSE and 5-day planetary waves: a case study, Geophys. Res. Lett, 29, 10, 50-1-4, 2002.

Kutepov, A. A., Gusev, O. A., and Ogibalov, V. P.: Solution of the non-LTE problem for molecular gas in planetary atmospheres: Superiority of accelerated lambda iteration, J. Quant. Spectrosc. Radiat. Transfer, 60, 199-220, 1998.

Mason, E. A. and McDaniel, E. W.: Transport properties of ions in gases, John Wiley, New York, 1988.

Mozer, F. S. and Serlin, R.: Magnetospheric electric field measurements with balloons, J. Geophys. Res., 74, 4739-4754, 1969.

Offermann, D. and Grossmann, K. U.: Thermospheric density and compositions as determined by a mass-spectrometer with cryo ion source, J. Geophys. Res., 78, 8296-8304, 1973.

Offermann D., Friedrich, V., Ross, P., and von Zahn, U.: Neutral gas composition measurements between 80 and $120 \mathrm{~km}$, Planet. Space Sci., 29, 747-764, 1981.

Offermann, D. K., Grossmann, U., Barthol, P., Knieling, P., Riese, M., and Trant, R.: Cryogenic Infrared Spectrometers and Telescopes for the Atmosphere (CRISTA) experiment and middle atmosphere variability, J. Geophys. Res., 104, 16311-16325, 1999.

Philbrick, C. R., Faucher, G. A., and Trzcinski, E.: Rocket measurements of mesospheric and lower thermospheric composition, Space Research, Akademie, Berlin, 13, 255-260, 1973.

Rapp, M., Gumbel, J., Lübken, F. J., and Latteck, R.: D-region electron number density limits for the existence of polar mesosphere summer echoes, J. Geophys. Res., 107, 10.1029/2001JD001323, 2002.

Reagan, J. B., Meyerott, R. E., Nightingale, R. W., Gunton, R. C., Johnson, R. G., Evans, J. E., and Imnof, W. L.: Effects of the August 1972 solar particle events on stratospheric ozone, J. Geophys. Res., 86, A3, 1473-1494, 1981. 
Rees, M. H., Emery, B. A., Roble, R. G., and Stammes, K.: Neutral and ion gas heating by auroral electron precipitation, J. Geophys. Res., 88, 6289-6300, 1983.

Rees, M. H.: Physics and chemistry of the upper atmosphere, Cambridge University Press, 1989.

Reid, I. M., Czechowsky, P., Rüster, R., and Schmidt, G.: First VHF radar measurements of mesopause summer echoes at midlatitudes, Geophys. Res. Lett., 16, 135-138, 1989.

Roble, R. G., Emery, B. A., Killeen, T. L., Reid, G. C., Solomon, S., Garsia, R. R., Evans, D. S., Hays, P. B., Carignan, G. R., Heelis, R. A., Hanson, W. B., Winningham, D. J., Spencer, N. W., and Brace, L. H.: Joule heating in the mesosphere and thermosphere during 13 July 1982, solar proton event, J. Geophys. Res., 92, A6, 6083-6090, 1987.

Röttger, J., La Hoz, C., Kelley, M. C., Hoppe, U.-P., and Hall, C.: The structure and dynamics of polar mesospheric summer echoes observed with the EISCAT $224 \mathrm{MHz}$ radar, Geophys. Res. Lett., 15, 1353-1356, 1988.

Röttger, J.: Radar observations of the middle and lower atmosphere, Incoherent scatter: theory, practice and science, Collection of lectures given in Cargese, Corsica, 1995, EISCAT Technical report 97/53, 1997.

Sharma, R. D. and Wintersteiner, P. P.: Role of carbon dioxide in cooling planetary atmospheres, Geophys. Res. Lett., 17, 22012204, 1990.

Shved, G. M., Khvorostovskaya, L. E., Potekhin, I. Y., Demynikov, A. I., Kutepov, A. A., and Fomichev, V.I.: Measurement of the quenching rate constant for collisions $\mathrm{CO}_{2}$ (0110)-O: The importance of the rate constant magnitude for the thermal regime and radiation of the lower thermosphere, Izv. Russ. Acad. Sci. Atmos. Oceanic Phys., Engl. Transl., 27, 431-437, 1991.
Shved, G. M., Kutepov, A. A., and Ogibalov, V. P.: Non-local thermodynamic equilibrium in $\mathrm{CO}_{2}$ in the middle atmosphere, I, Input data and populations of the nu-3 mode manifold states, J. Atm.. Sol. Terr. Phys., 60, 289-314, 1998.

Smart, D. E., Shea, M. A., Fluckiger, E. O., Tylka, A. J., and Boberg, P. R.: Changes in calculated vertical cutoff rigidities at the altitude of the international space station as a function of geomagnetic activity, Proceedings of the 26th ICRC, Salt Lake City, USA, 1999a.

Smart, D. E., Shea, M. A., and Fluckiger, E. O.: Calculated vertical cutoff rigidities for the international space station during magnetically quit times, Proceedings of the 26th ICRC, Salt Lake City, USA, 1999b.

Smart, D. E., Shea, M. A., Fluckiger, E. O., Tylka, A. J., and Boberg, P. R.: Calculated vertical cutoff rigidities for the international space station during magnetically active times, Proceedings of the 26th ICRC, Salt Lake City, USA, 1999c.

Tammet, H.: Size and mobility of nanometer particles, clusters and ions, J. Aerosol. Sci., 3, 459-475, 1995.

Thomas, L., Astin, I., and Prichard, T.: The characteristics of VHF echoes from the summer mesopause region at mid-latitudes, J. Atmos. Terr. Phys., 54, 969-977, 1992.

Trinks, H. and Fricke, K. H.: Carbon dioxide concentrations in the lower thermosphere, J. Geophys. Res., 83, 3883-3886, 1978.

Von Zahn, U.: Meeting highlights, Layered Phenomena in the Mesopause Region workshop, Asilomar, California, 10-12 October 2001.

Winser, K. J., Jones, G. O. L., and Williams, P. J. S.: A quantitative study of the high latitude ionospheric trough using EISCAT's common programmes, J. Atmos. Terr. Phys., 48, 893-904, 1986. 